\title{
T.В. Мамина
}

Томский государственный университет

\section{Реализация компонента «реальность/нереальность желания» в структуре сценария «карьера»}

Аннотация: В статье рассмотрена реализация признаков концепта «желание» и компонента «реальность/нереальность желания» в сценарии «карьера». Рассмотрены способы вербализации данного компонента в сопоставительном аспекте, описана двухступенчатая структура определения предмета желания: «преджелание» и желание в ходе развертывания типичной ситуации карьерной стратегии.

The article is focused on the actualization of the conceptual information and the component "wish reality/unreality" which is represented in the script structure "career". The author considers the ways of this component verbalization within the framework of the contrastive-comparative aspect; there is a description of the two-stage structure of the wish object: "pre-wish" and the wish which appears during the development of a career strategy typical situation.

Ключевые слова: модель сценария, способы вербализации концептуальной информации, агент сценария, реальность/нереальность желания.

Cognitive model of script, concept verbalization ways, script agent, wish reality/unreality.

УДК: 81-119.

Контактная информащия: 634050, г.Томск., ул.Ленина, 36.ТГУ, филологический факультет. Тел. 8 (3822)534771. E-mail: takluewa@yandex.ru.

Языковое высказывание понимается и интерпретируется носителем языка посредством обращения к знанию, информации, полученной им в процессе познавательной деятельности. Понимание, как отмечает Т.А. ванн Дейк, «неизбежно базируется на более общих концептах, категориях, правилах и стратегиях. Это общее "знание" не является аморфным, оно организовано в концептуальные системы» [Dijk, 1977, с. 16; перевод наш. - T.M.]. Факт разнородности фрагментов действительности рефлексируется разными моделями структурирования знаний. Таким образом, коммуникативное действие в рамках спонтанного или организованного дискурса представляет собой реализацию тех или иных коммуникативнокогнитивных структур, которыми являются фреймовые модели, содержащие информацию социокультурного характера.

Модель культурно-обусловленного знания о какой-либо типовой ситуации национальной культуры, являющегося общим для языкового сообщества, представляет собой сценарий. Он рассматривается как единство культурного и языкового аспектов. По мнению Д. Лакоффа, в основе сценария как пропозициональной модели лежит структурная схема пути: источник - путь - цель, где источником является исходное состояние, целью - конечное состояние, а события между ними рассматриваются как точки на пути [Lakoff, 1987, с. 286]. Таким образом, движение агента сценария к цели в рамках обозначенной схемы обусловлено наличием мотивационного фактора. 
Целью исследования является описание структуры сценария «карьера» в русской лингвокультуре посредством анализа способов вербализации реальности / нереальности желания. Материалом послужили 62 текста Интернет-форумов в рамках данной тематики. Отбор текстов осуществлялся по теме форума, по частотному употреблению лексемы «карьера».

Рассмотрим реализацию концепта «желание» в структуре сценария «карьера». «Желание» отражает в своей структуре и своем содержании сложное соотношение языкового и неязыкового знания, подразумевающее «как сведения об объективном положении дел в мире, так и сведения о воображаемых мирах и возможном положении дел в этих мирах» [Алтабаева, 2004, с. 107]. Таким образом, концептуальная информация, содержащаяся в представленной форме структурирования знаний, обладает специфическими чертами: с одной стороны, признаки концепта «желание» носят обобщенный, абстрактный характер, с другой - конкретизируются через «предмет желания», занимающий в системе отношений объективного мира определенное место, обозначенное агентом сценария в контексте построения карьерной стратегии. Синонимический ряд глагольных лексем в русском языке с семантикой желания представляет собой следующую цепочку, единицы которой расположены по степени нарастания интенсивности желания: желать, хотеть, намереваться, стремиться, мечтать, жаждать, вожделеть [Мастерских, 2004, с. 206]. Наиболее частотным языковым репрезентантом желания выступает глагол «хотеть» в изъявительном наклонении, имеющий нейтральную стилистическую окраску:

Я всегда вижу, какой хочу быть через 10 лет, ставлю себе цель и маленькими шагами к этой цели иду.

70\% написали, что они пока не знают, кем они будут, но те 30\%, которые написали, как они себя видят через много лет, добились, чего хотели, какими бы нереальными не были их иеели.

С возрастом доля тех, кто достиг того, чего хотел, заметно возрастает.

В представленных контекстных реализациях конкретизация желаемого осуществляется посредством вербализации временного компонента: отрезок времени с момента определения желаемого, то есть точки нахождения агента сценария, и его воплощения в реальность. Наличие объективированной в языке темпоральной характеристики свидетельствует о восприятии агентом сценария предмета желания как реального, возможного при определенных условиях. Таким образом, карьера видится агентом сценария как некая стратегия, основа которой заключается в четком прогнозировании на продолжительные периоды. Желаемое в рамках сценария «карьера» представляет собой запланированное реальное, точку пути, соответствующую новой сцене сценарной структуры. Оно направлено на выполнимый объект, связано с волей и готовностью субъекта прилагать усилия для достижения цели, преднамеренностью и подконтрольностью [Красильникова, 2009, с. 66]. Отсутствие в исследованных контекстах придаточных дополнительных предложений с союзом «чтобы», объясняющих предмет желания, указывает на четкое представление агента сценария о желаемом.

Семантика подконтрольности и реальности желаемого актуализируется также в единицах «план», «планировать», «рассчитывать»:

Это и серьезное развитие в области маркетинга и продаж, и собственная производственная база в Волоколамске, и региональное присутствие: первый филиал открыт в Санкт-Петербурге, второй филиал мы планируем открыть во второй половине этого года в Екатеринбурге.

Конечно, мы не существуем в вакуумном пространстве, и наши планы роста зависят от развития российского рынка.

Указанный выше признак реализуется в структуре немецкого сценария «Karriere». Реальность желаемого выражается модальным глаголом «wollen», в значении «намереваться совершить то или иное действие (cp. wollen - 1. die Absicht, 
den Wunsch haben, etw. zu tun, zu werden), требование получить что-либо (cp. j-d will etw. haben - 2. j-d verlangt od. äußert den Wunsch, dass er etw. bekomme) [Götz, 2002, S. 1144].

Bis jetzt machen wir alles nur für uns selbst, aber vielleicht wollen wir auch bald externe Kunden an Land ziehen und die Abteilung in eine GmbH mit mir als Geschäftsführer umgewandelt werden!

Dafür ist eine Entscheidung notwendig, die aussagt, was der Einzelne kann, was er will und was er bereit ist dafür zu tun.

Falls wir Sie neugierig gemacht haben und Sie Ihre Chance zur beruflichen Karriere bei uns wahrnehmen wollen, senden Sie bitte Ihre vollständigen Bewerbungsunterlagen an die entsprechende Personalabteilung der MAN Turbo (siehe Kontaktadressen oben auf dieser Seite).

Таким образом, семантика ирреальности желания не находит языкового выражения в контексте сценария «карьера» ни в одном из рассматриваемых языков. Ирреальное представляется носителем языка как потенциальное реальное. С этим связано отсутствие в структуре сценария параметров «осуществимости / неосуществимости» желания.

Осознание реальности желаемого, основательный подход к созданию модели его достижения комплексно объективируют концептуальный признак субъективной положительной оценки выбранного ориентира. В этой связи следует говорить признаке гедонистической оценочности, в аспекте которого предмет желания воспринимается агентом как вариант позитивного хода развития сценария [Арутюнова, 1988, с. 55-58]. Таким образом, выбирая из множества предметов объективной реальности предмет желания и обозначая его, агент сценария актуализирует свои индивидуальные ценностные установки, а также и те, которые определены социальным устройством, традициями языкового сообщества.

Я всё время хочу находиться в состоянии весны, мне всё время хочется, чтобы у меня всё начиналось.

За год до кризиса (летом 1997 года) я совершенно случайно оказалась в одном известном агентстве, и, войдя туда, вдруг поняла, что это именно тот мир, в котором я хотела бы жить.

Что касается приоритетов, мне хочется сохранить существующие отношения внутри компании, хочется, чтобы люди, приходя к нам, понимали, что они социально ответственны и что они делают некое благо.

Но в моем возрасте хотелось больще действия, да и амбиции были соответствующими.

В приведенных примерах вербализуется особое состояние агента сценария «карьера» - «пред-желание» (безличная форма глагола «хотелось», сослагательное наклонение «хотелось бы», глагол «желать»), связанное с начальной стадией действия агента. На данном этапе речь идет не о разработке алгоритма продвижения по схеме сценария, плана действия, обеспечивающего переход из одной сцены в другую, а осуществляется лишь определение мотива, постановка цели с ориентацией на существующую в социуме систему ценностей и представлений. Е.В. Красильникова описывает признаки желания «начального» этапа как относительную автономность, неподконтрольность агенту, отсутствие непосредственной ориентации на выполнение и волевые усилия агента [Красильникова, 2009, с. 66]. Правомерность выделения этих признаков доказывается выбранной носителем русского языка безличной формы глагола «хотеться» для вербализации желаемого. Агент сценария обращается к существующим в независимости от него ценностным ориентирам национального сообщества. При осмыслении и личном принятии их как позитивных общепринятых положений, агент выбирает личные формы глагола «хотеть», подчеркивая сформировавшееся у него представление о пути достижения желаемого. 
Функционирование предикатов «желать», «хотеть(ся)», выражающих внутреннее состояние агента на первоначальном этапе деятельности, характерно также и для немецкой лингвокультуры (глагол «wünschen», форма сослагательного наклонения от глагола «mögen» «möchten»:

Wir wünschen uns Bewerber, die neugierig auf Fortschritt sind und sich mit dem einmal Erreichten nicht zufrieden geben. Neben guten Leistungen im Studium erwarten wir daher auch lebenslange Lernbereitschaft, Eigeninitiative sowie ausgeprägte Teamfähigkeit.

Als Naturwissenschaftler/in, Ingenieur/in oder Techniker/in sind Sie hoch qualifiziert. Sie engagieren sich, möchten eigenverantwortlich sein und selbstständig arbeiten. Dabei bauen Sie auf Teamgeist. Sich für Kolleginnen und Kollegen einzusetzen, ist eine Selbstverständlichkeit.

При вербализации предмета желания объективируются также признаки самого агента сценария «карьера» (например, молодость, мобильность и активность агента), признаки концепта «компания» (дружеская домашняя атмосфера, социальная ответственность) и т.д.

В рамках сценария «карьера» желаемое рассматривается агентом как некая целевая установка, адресованная в первую очередь самому агенту сценария, которая фиксируется в памяти агента. Таким образом, речь идет о самоадресации, самонаправленности желания. Иными словами, формирующееся желание определенным образом воздействует на агента, который, во исполнение желаемого, может воздействовать на других участников сценария вербальными и невербальными средствами.

Можно сделать вывод о том, что выбор концептуальных признаков «желание», актуализирующихся в сценарии «карьера», обусловлен структурой сценарной формы представления знаний. На языковом уровне желание представлено преимущественно глаголами «хотеть» и «желать». Предмет желания рассматривается агентом сценария как потенциальное возможное, отмеченное им на временной оси стереотипной ситуации. Временные характеристики конкретизируют предмет желания, подчеркивая его реальность.

В ходе развертывания типичной ситуации карьерной стратегии объективируется двухступенчатая структура определения предмета желания: «пред-желание» и желание. На ступени «пред-желания», вербализованной безличными формами и формами сослагательного наклонения глагола «хотеться», агентом сценария концептуализируется мотив желания, реализуется постановка цели. При этом в контекстных реализациях объективируются ценности и традиционные представления языкового сообщества, оцениваемые агентом как бесспорно позитивные. Для второй ступени формирования желания характерна языковая репрезентация непосредственной ориентации агента на выполнение цели и его волевые усилия. При этом вербализуемое агентом сценария «карьера» желаемое мыслится им как адресованное себе.

\section{Литература}

Алтабаева Е.В. Когнитивные параметры концепта «желание» // Русский язык: исторические судьбы и современность: 20-й Междунар. конгресс исследователей рус. яз. (МГУ им. Ломоносова). М., 2004.

Арутюнова Н.Д. Типы языковых значений: Оценка. Событие. Факт / Отв. ред. Г.В.Степанов. М., 1988.

Красильникова Е.В. Сопоставительное исследование концептов «желание» и «воля» (на материале русского и английского языков) // Вестн. Челябинского гос. ун-та. 2009. № 22 (160). Сер.: «Филология. Искусствоведение». Вып. 33.

Мастерских С.В. Описание сущности концепта «желание» // Вестн. Тюменского гос. ун-та. 2006. № 4. 
Dijk T.A. van. Semantic macro-structures and knowledge frames in discourse comprehension // Cognitive processes in comprehension / Ed. P. Carpenter and M. Just. N.J., 1977.

Götz D. Langenacheidts Großwörterbuch. Deutsch als Fremdsprache für alle, die Deutsch lernen. Berlin, 2002.

Lakoff G. Women. Fire, and Dangerous Things: What Categories Reveal About the Mind. Chicago, 1987. 